\title{
ARTE Y ESTÉTICA EN LOS MINUTOGRAMAS DE JORGE OTEIZA
}

\author{
JoSÉ JAVIER AZANZA LÓPEZ ${ }^{1}$ \\ Universidad de Navarra
}

\begin{abstract}
Durante su estancia en Buenos Aires en 1939, Jorge Oteiza promovió el servicio de información artística El Arte marcha, resultado del cual son los Minutogramas, en los que con una estética cercana al cómic, un marcado interés por el grafismo y un discurso al que no son ajenos los ecos del surrealismo y del "ramonismo" de Gómez de la Serna, aporta diversas claves de su pensamiento estético. Su fe en los valores universales de la geometría de la mano de Leonardo, la naturaleza como fundamento de la creación escultórica que descubre en Maillol, Zadkine, Alberto y Erzia, su admiración hacia El Greco, Velázquez y Goya como referentes hispanos, el reconocimiento de Cézanne como el padre del Arte Contemporáneo y el magisterio de Hans Arp constituyen otros tantos asuntos de sus Minutogramas, en los que manifiesta igualmente su dimensión humanista que abarca múltiples áreas de conocimiento.
\end{abstract}

Palabras clave: Jorge Oteiza; España y Argentina; Siglo XX; Arte; Estética; Surrealismo; Minutogramas.

\section{ART AND AESTHETICS IN THE MINUTOGRAMAS OF JORGE OTEIZA}

During his stay in Buenos Aires in 1939, Jorge Oteiza promoted the artistic information service The art walk, a consequence of which are his Minutogramas. They are close to the comic aesthetic, show a remarkable interest in graphic design, and display a discourse that echoes Surrealism and the "ramonismo" of Ramón Gómez de la Serna. In this way, the sculptor provides some keys to understanding his aesthetic thinking: his belief in the universal values of Geometry following in the footsteps of Leonardo; Nature as the foundation for sculptural creation which he discovers in Maillol, Zadkine, Alberto and Erzia; his admiration for El Greco, Velázquez and Goya as Hispanic models; the recognition of Cézanne as the father of Contemporary Art and the teachings of Hans Arp, constitute some of the themes found in his Minutogramas, in which he also manifests his humanistic dimension in several areas of knowledge.

Key words: Jorge Oteiza; Spain and Argentina; 20th Century; Art; Aesthetic; Surrealism; Minutogramas.

Como citar este artículo / Citation: Azanza López, José Javier (2018): “Arte y estética en los Minutogramas de Jorge Oteiza". En: Archivo Español de Arte, vol. 91, núm. 361, Madrid, pp. 47-64. https://doi.org/10.3989/aearte. 2018.04

En 1939, y con el objetivo de generar recursos económicos con los que poder subsistir en Buenos Aires, el escultor Jorge Oteiza (Orio, Guipúzcoa, 1908-San Sebastián, 2003) promueve la fundación de la Agencia Internacional de Arte AIDA. En el marco de la misma se inscribe El arte marcha, iniciativa encaminada a suministrar a otras publicaciones un servicio de información cultural que supliese la habitual falta de una sección de arte en los periódicos, superando la competencia del crítico local; no en vano, decía contar con la colaboración de los mejores escritores y artistas internacionales para elaborar una sección diaria de arte "original, amenísima e instructiva, presentada de una forma fácil y moderna"².

\footnotetext{
1 jazanza@unav.es/ ORCID iD: http://orcid.org/0000-0002-0375-7899.

2 Archivo Fundación Museo Jorge Oteiza, Alzuza (AFMJO), FD-22792. AIDA: Agencia Internacional de Arte. Buenos Aires, 1939.
} 
El arte marcha cuidaba de manera especial su presentación, que adquiría sentido de cartel mural a modo de reclamo publicitario para captar la atención de los lectores. Acentuaba en consecuencia su grafismo, y apostaba por la combinación de texto e imagen para lograr un alto valor instructivo.

Surgen en este contexto los Minutogramas de Estética, una especie de viñetas de cómic que abordaban asuntos relativos al arte y que define como "fabulario del arte, disparatografías, historia alucinada del hombre y del arte"3. Aprovechaba Oteiza el gusto particular del lector por el formato tipo historietas con un claro objetivo: "En estos carteles representaremos gráficamente un minuto de nuestro tiempo cultural... Con unas letras y unas líneas y desde todos los ángulos posibles, emprendemos hoy la tarea de expresar un minuto verdadero en la marcha de nuestra vida espiritual"4.

En nuestra aproximación a los Minutogramas, algunas ideas previas aportarán las claves para su interpretación. Sin duda subyace en ellos la vinculación a los círculos dadaístas y surrealistas chilenos durante su estancia en Santiago entre 1935 y 1937, en especial al poeta Vicente Huidobro (1893-1948), a cuyas reuniones de artistas y literatos celebradas en su casa asistió el escultor. No podemos obviar tampoco la influencia del "ramonismo" de Gómez de la Serna (1888-1963), peculiar estilo literario caracterizado por la escritura fragmentaria y poética y por el juego humorístico y gráfico, todo lo cual conduce a los dominios de la sugestión y el símbolo ${ }^{5}$. La biblioteca personal de Oteiza registra entre sus obras La Sagrada Cripta de Pombo, Caprichos y Gollerías $^{6}$, fiel reflejo de su interés por el "ramonismo".

Apuntemos finalmente una idea que resulta consustancial al método de trabajo oteiciano, como es el enorme protagonismo que adquieren escritura y grafismo en el desarrollo de su obra?. La combinación de textos con dibujos y gráficos forma parte de su proceso creador y hace acto de presencia en cartas, documentos e incluso en las anotaciones manuscritas en los libros de su biblioteca. Los Minutogramas se inscriben plenamente en este particular método reflexivo que ofrece un marcado carácter visual.

Oteiza, como ha quedado dicho, compuso sus Minutogramas en Buenos Aires en 1939, fecha que figura al pie de uno de ellos. Custodiados en el Archivo de la Fundación Museo Jorge Oteiza (Alzuza, Navarra) (fig. 1), prestaremos especial atención a aquellos de naturaleza estéticoartística, analizando su contenido, rastreando sus posibles fuentes y posterior alcance, y valorando su inserción en los mecanismos del pensamiento oteiciano ${ }^{8}$.

\section{Una lección de geometría: Leonardo da Vinci y el rectángulo de oro}

Los valores universales de la geometría, puestos en relación con la figura de Leonardo da Vinci, constituyen uno de los temas a los que Oteiza presta mayor atención en sus Minutogramas, hasta en cuatro ocasiones con mínimas variantes (fig. 2).

\footnotetext{
3 AFMJO, FD-14822. Mitogramas. Badiola, 2015: 78-80.

4 AFMJO, FD-14820. En estos carteles.

5 Arias, 2001: 13.

${ }^{6}$ La Sagrada Cripta de Pombo, T. II, Madrid, G. Hernández y Galo Sáez, 1923, FB-5403, Sign. 4900; Caprichos, Madrid, Almarabu, 1986, FB-3816, Sign. 3624; Gollerías, Buenos Aires, Losada, 1946, FB-1546, Sign. 1396. Recogemos en todos los casos la edición conservada en la biblioteca personal de Oteiza, con su correspondiente número de registro y signatura. Al no tratarse de bibliografía propiamente dicha, mantenemos el criterio de cita de la biblioteca del Museo Oteiza, y omitimos su presencia en la relación bibliográfica final.

7 Así lo entiende Álvarez, 2003: 179.

${ }^{8}$ La información contenida en los Minutogramas se distribuye en diferentes documentos: AFMJO, FD-5182. Mitogramas [Minutogramas]; FD-14821. A un artista en la luna; FD-14825. Opinan sobre arte las mujeres; FD-14826. [Minutogramas de estética]; FD-14827. El arte marcha; FD-15070. Maruja Mallo; FD-22790. El arte marcha: Minutogramas de estética $=$ Oteitza FD 22791. Minutogramas de estética $=$ Oteitza [2. ${ }^{a}$ versión]. Remitimos al lector a su consulta, evitando la posterior reiteración en la cita.
} 

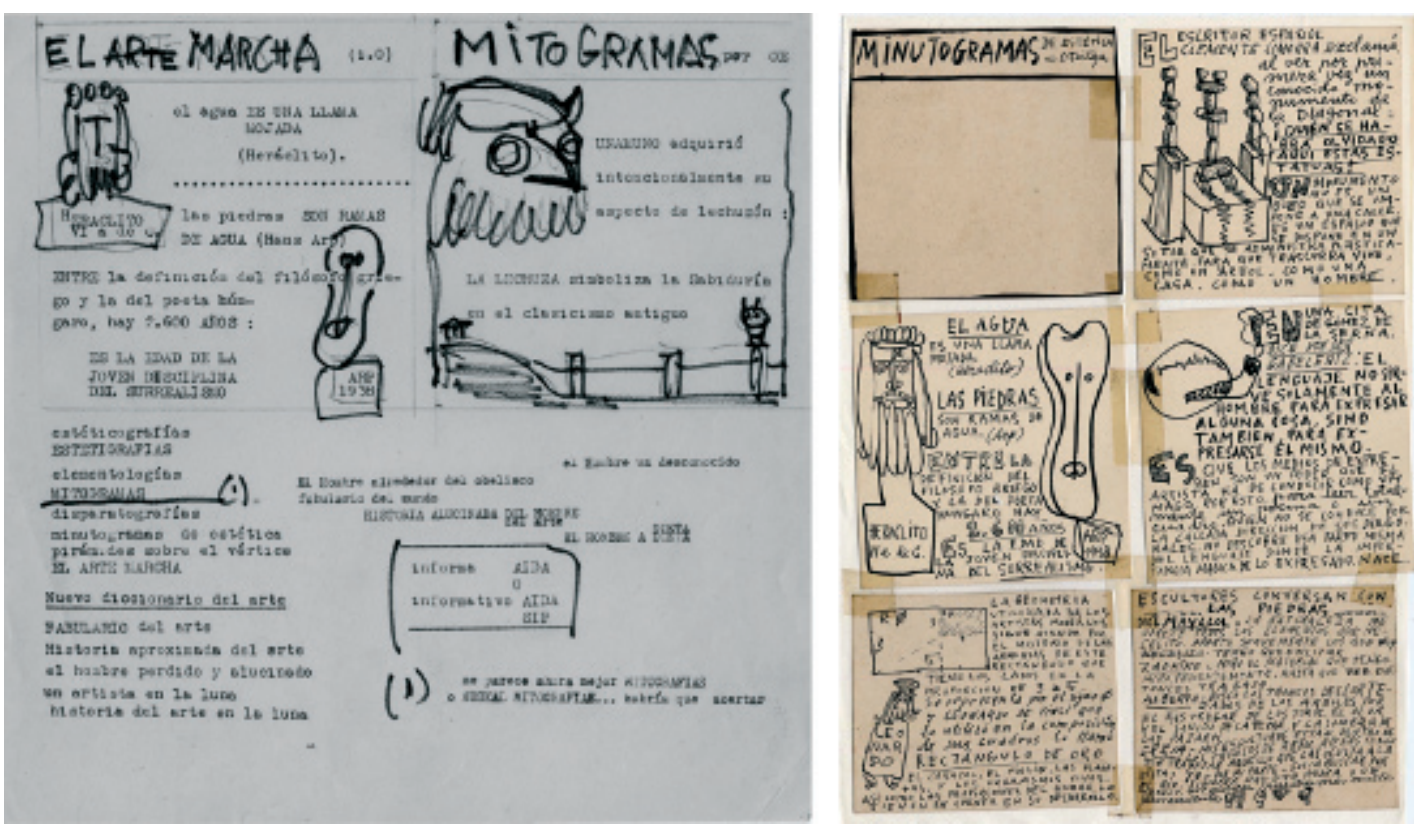

Fig. 1. Jorge Oteiza. Boceto y grupo de minutogramas. Archivo Fundación Museo Jorge Oteiza (AFMJO), FD-14827 y FD-22790.

Fig. 2. Jorge Oteiza. Boceto y minutogramas sobre la geometría y Leonardo. AFMJO, FD-14821, FD-22790 y FD-22791.
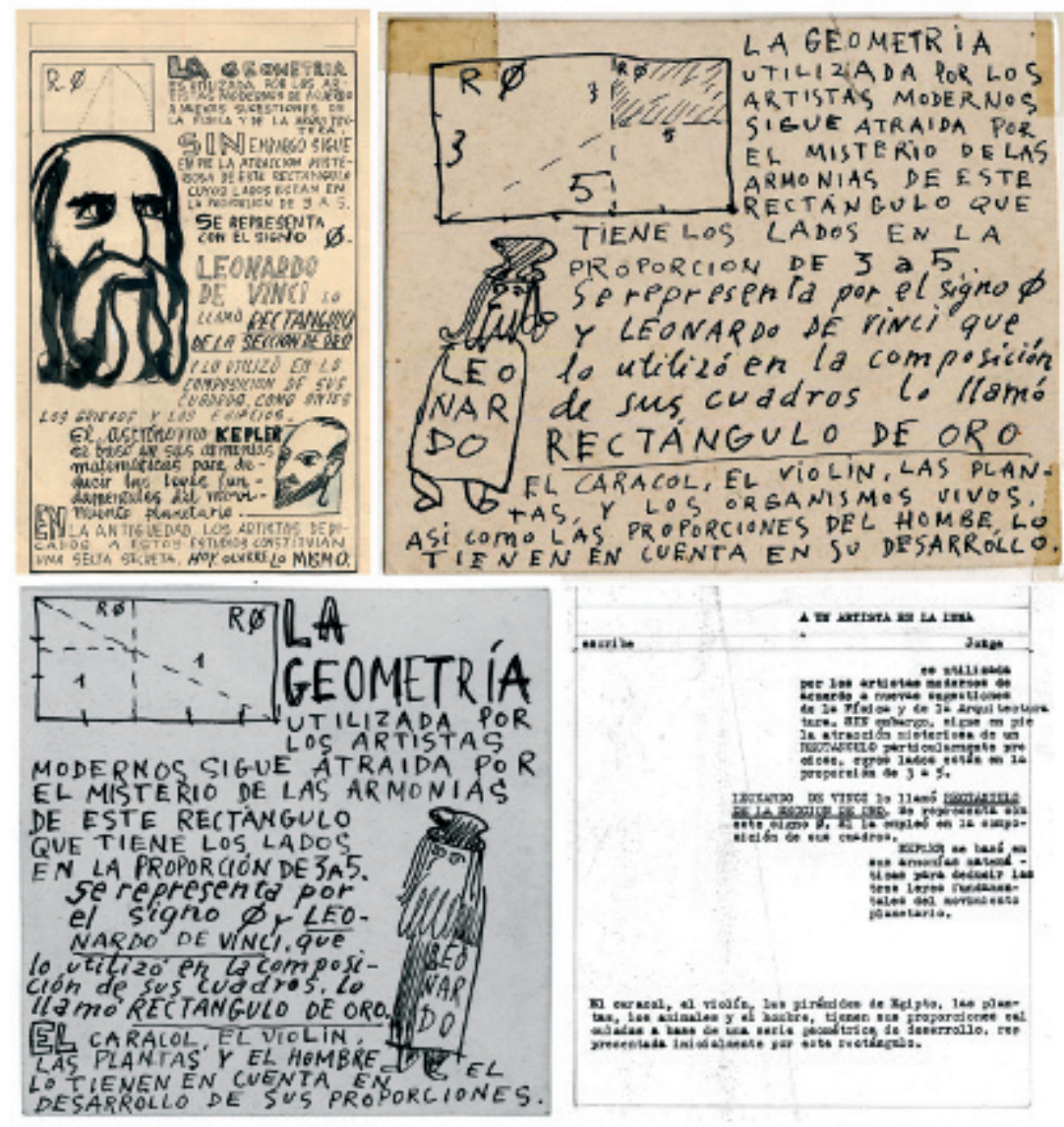

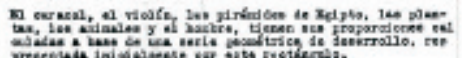


El punto de partida se encuentra en el reconocimiento de la vigencia y aplicación en el arte moderno de los principios de la geometría, siguiendo las leyes de la física y de la arquitectura; y es aquí donde se evidencia la atracción hacia el rectángulo denominado por Leonardo de la sección de oro (aquel cuyos lados están en proporción de 3 a 5), al que recurrió el genio renacentista como anteriormente lo hicieron egipcios y griegos ${ }^{9}$. Certifica Oteiza que organismos vivos como el hombre, las plantas y los animales, construcciones como las pirámides de Egipto y objetos como el violín, calculan su sistema de proporciones a partir de una serie geométrica representada inicialmente por este rectángulo; y que sus armonías matemáticas le sirvieron al astrónomo alemán Johannes Kepler (1571-1630) para deducir las tres leyes fundamentales del movimiento planetario.

En tres de las cuatro versiones, el texto se acompaña de la representación del rectángulo de oro con sus cálculos matemáticos y de un "retrato" de Leonardo, ya sea de busto o de cuerpo entero, al que se suma en una de ellas un segundo "retrato" de Kepler. En esta última Oteiza cierra su comentario con una alusión al carácter excepcional de los artistas dedicados a los cálculos matemáticos, entre los que se encuentra el propio escultor.

Pudiéramos pensar, dada la reiteración en la cita leonardesca, que Oteiza extrajo la enseñanza relativa al rectángulo de oro del tratado del artista italiano; de hecho, contaba en su biblioteca personal con El tratado de la pintura (Buenos Aires, More-Mere, 1942, FB-4149, Sign. 3865), versión española de la edición de 1828. Sin embargo, su verdadera fuente de información proviene del filósofo e historiador rumano Matila Ghyka (1881-1965), cuyos trabajos venían a demostrar que la divina proporción era el fundamento de toda obra ${ }^{10}$.

Reconoce el escultor — estableciendo un paralelismo con Le Corbusier- que cuando tuvo conocimiento de su teoría en América todavía no estaba preparado para su comprensión matemática, pero sí mediante las figuras que la interpretaban ${ }^{11}$; y, de hecho, así se deduce de los numerosos comentarios y cálculos personales que incluye en Le nombre d'or (I) (París, Librairie Gallimard, 1931, FB-393, Sign. 1361), uno de los tres libros de Ghyka que formaban parte de su biblioteca personal ${ }^{12}$, del que tomó la mayoría de los datos que conforman el Minutograma leonardesco. En efecto, entresaca de sus páginas las alusiones a Leonardo (p. 50), a Kepler (p. 50) y a la arquitectura egipcia y griega (pp. 50,75-76, plancha XLIV), así como al hecho de que los valores de la geometría han sido transmitidos por Leonardo y por el matemático italiano Luca Pacioli (p. 53); y son numerosos los cálculos que realiza a partir de los gráficos y diagramas del libro (planchas II, XII, XXV), por medio de cuyas imágenes constata la presencia de la armonía de proporciones en plantas y caracoles (planchas XIII-XVI) y el sistema de proporciones del cuerpo humano basado en la divina proporción (p. 50, planchas XVII-XXII).

Corrobora el interés de Oteiza por la sección de oro el hecho de que uno de los primeros escritos en los que reflexiona en torno a dicho concepto data de hacia 1938, cronología muy próxima a la del Minutograma ${ }^{13}$. La relación y proporción numéricas, la armonía matemática y el concepto geométrico-artístico de la sección áurea fueron temas de constante estudio y aplicación práctica en el escultor, buena prueba de su obsesión por la formulación matemática universal ${ }^{14}$. Así lo comprobamos en su proyecto para el concurso de monumento a Felipe IV (1949),

${ }^{9}$ El rectángulo de la sección de oro era aquel cuyos lados poseían una proporcionalidad igual al número de oro (Phi, 1,618033989), valor algebraico irracional descubierto en la antigüedad como relación o proporción, dadas sus propiedades matemáticas y algebraicas que siempre atrajeron a Oteiza, al igual que la serie dinámica creciente de Leonardo de Pisa (Fibonacci).

${ }^{10}$ Matila Ghyka destacó por su estudio de la sección áurea, a la que dedicó numerosos textos, entre ellos su Estética de las proporciones en la Naturaleza y en las Artes (1927) y El número de oro (1931). Álvarez, 2010: 190. Díaz Ereño, 2010: s.p. Martínez Gorriarán, 2011: 68, 90 y 97.

11 Así lo confiesa en una anotación a El Modulor, Buenos Aires, Poseidón, 1953, p. 25. FB-4683, Sign. 4357.

${ }^{12}$ Los otros dos son de cronología posterior a la elaboración de los Minutogramas, por lo que quedan descartados como posibles fuentes. Se trata de Estética de las proporciones en la naturaleza y en las artes, Buenos Aires, Poseidón, 1953, FB-392, Sign. 1360; y El número de oro (II), Buenos Aires, Poseidón, 1968, FB-394, Sign. 1362.

13 AFMJO, FD-8881. Notas sobre la sección de oro. Año 1938.

14 Esclarecedor resulta en este sentido el trabajo de Sánchez Simón, 2012. 
Fig. 3. Jorge Oteiza.

Minutograma sobre

las "pirámides" del arte hispano. AFMJO, FD-22791.

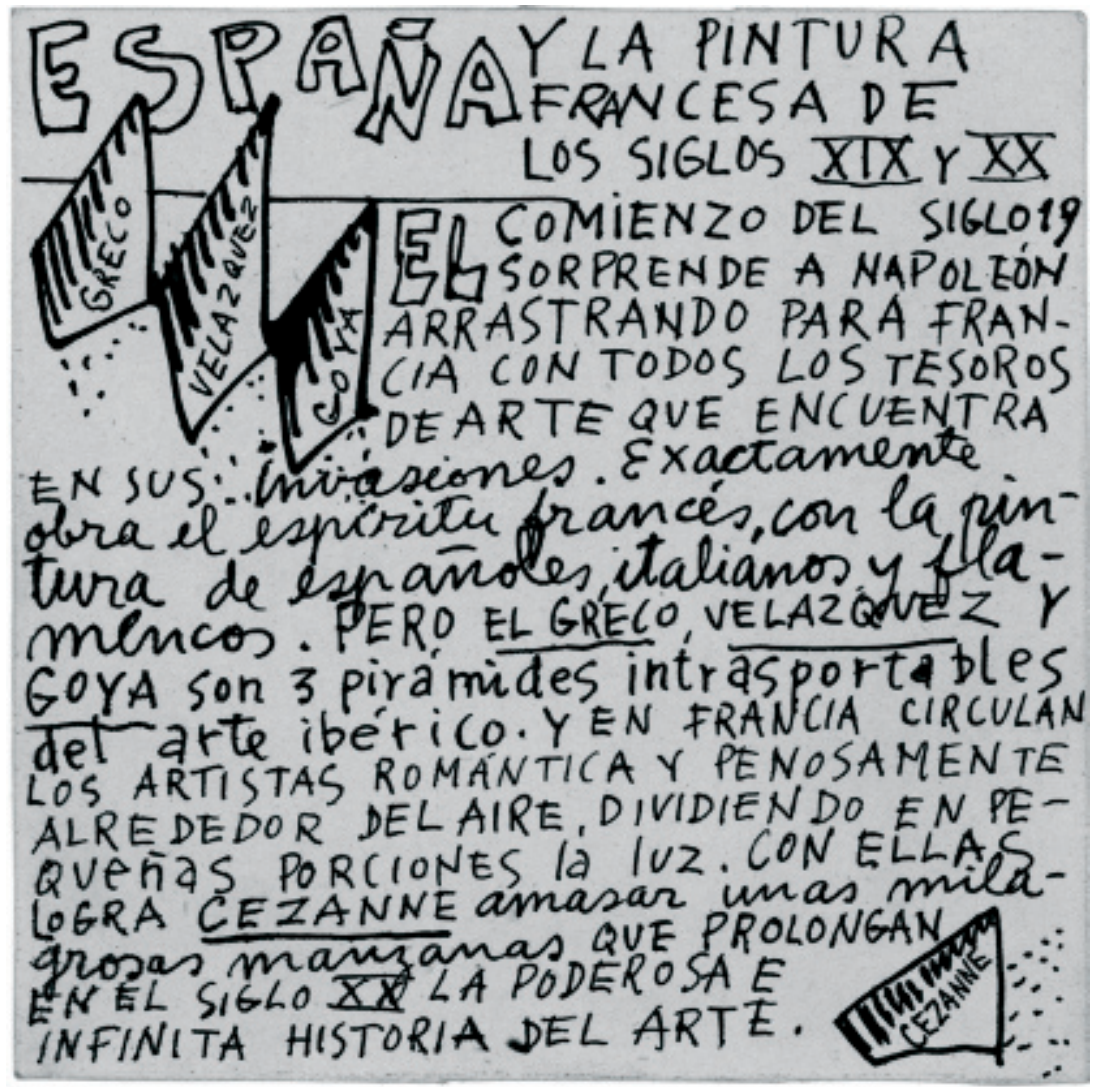

donde para concretar su ubicación desarrolla un complejo cálculo matemático basado en el rectángulo áureo, que como tal interpretaba el espacio de la Plaza de la Constitución - entonces del 18 de Julio - de San Sebastián al que estaba destinado la estatua ${ }^{15}$; en el muro-soporte que debía acoger el Friso de los Apóstoles de la basílica de Aranzazu; en el proyecto de capilla para el Camino de Santiago; y en algunas esculturas tardías, caso de Par móvil (1956) y Arista vacía (1958), cuyas proporciones basadas en la sección áurea permiten comprobar la pervivencia en Oteiza de su interés por las relaciones de proporción ${ }^{16}$. Todo ello le lleva a afirmar a Sáenz Guerra que "los conceptos de módulo, número de cabezas y sección áurea aportan una visión de escultor tremendamente canónico" $"$.

\section{De las "pirámides" del arte español a Cézanne}

El saqueo y traslado a Francia de multitud de obras de arte llevado a cabo por las tropas napoleónicas a comienzos del siglo XIX, mueve a Oteiza a realizar una reflexión en torno al arte español y a la pintura francesa de los siglos XIX y XX (fig. 3).

Considera el escultor que esta "apropiación" puede trasladarse al ámbito de las ideas artísticas, por cuanto así también "obra el espíritu francés, con la pintura de españoles, italianos y

\footnotetext{
15 Azanza López, 2013. López Bahut, 2016: 44-45.

16 Álvarez, 2010: 214-215.

17 Sáenz Guerra, 2007: 139.
} 
flamencos"; es decir, el arte francés se adueña de las citadas escuelas europeas a la hora de alumbrar su propia creación. Pero, llegados a este punto, Oteiza salvaguarda del "expolio" a las "3 pirámides intrasportables del arte ibérico", que como tales califica a El Greco, Velázquez y Goya, inamovibles en sus fundamentos y genialidad artística.

No debe sorprender la mención oteiciana a los tres artistas por cuanto, si bien su marcha a América en 1935 tenía como objetivo elaborar una nueva teoría estética basada en la estatuaria megalítica y el muralismo mexicano, no renuncia a sus referentes hispanos, con los que tomó contacto en el Museo del Prado durante su etapa de formación en Madrid ${ }^{18}$. En su estancia americana adquiere libros sobre El Greco (Ludwig Goldscheider, Ramón Gómez de la Serna) y Goya (Juan de la Encina, Leonardo Estarico, Genaro Estrada o el propio Gómez de la Serna), en cuyas páginas anota multitud de comentarios que constituyen la base de sus conferencias pronunciadas en Bogotá en 1946 con motivo del II Centenario del nacimiento del pintor aragonés ${ }^{19}$, y que culminarán en su ensayo Goya mañana. El realismo inmóvil, finalizado en 1949 aunque no publicado hasta $1997^{20}$. De hecho, el retorno a España en 1948 no hará sino acrecentar la necesidad de reencontrarse con sus modelos: rinde visita a la tumba de Goya en San Antonio de la Florida (1948), lleva a cabo su personal interpretación de la iconografía real velazqueña a partir del $R e$ trato de Felipe IV de castaño y plata en el concurso donostiarra para el monumento a Felipe IV $(1949)^{21}$, y visita la Casa-Museo de El Greco en Toledo (h. 1952) 22; y es que la "rebeldía" de El Greco, la "arquitectura del vacío" de Velázquez y la "genial torpeza" de Goya definen en buena parte su posterior devenir artístico. Oteiza encuentra además en estas tres "pirámides" los antecedentes de la pintura moderna que desarrollarán más tarde artistas como Cézanne, Picasso o Juan Gris.

Precisamente el primero de ellos protagoniza la reflexión acerca de la pintura francesa que completa el Minutograma, y que parte de una crítica al impresionismo, a cuyos pintores siempre achacó que no sacaran todas las ventajas de su paleta luminosa, como recoge una anotación personal en De Eugenio Delacroix al neoimpresionismo (Buenos Aires, Poseidón, 1943, FB-759, Sign. 2668) de Paul Signac (p. 50). Por el contrario, reconoce el origen del arte moderno en el postimpresionismo de Van Gogh, Gauguin y Cézanne, en especial en este último, cuya nueva visión refleja en su convicción de conquistar París con "unas milagrosas manzanas que prolongan en el siglo XX la poderosa e infinita historia del arte". Cézanne se convierte en una nueva "pirámide" cuyo pensamiento posibilita el inicio del arte contemporáneo - "todos arrancamos de Cézanne y del Cubismo"23 - y supone una continuidad con las tres "pirámides" hispanas que culminará en Picasso.

\section{El universo surrealista: de Heráclito a Hans Arp}

Pese a que Oteiza manifestó una postura crítica hacia el surrealismo ${ }^{24}$, este hace acto de presencia en sus Minutogramas hasta en cinco ocasiones, con mínimas variantes (fig. 4).

18 "El Museo del Prado son las salas del Greco, Velázquez y Goya". Oteiza, 1997: 127.

19 La primera, el 29 de marzo, invitado por la Casa de España; la segunda, el 16 de abril en el Teatro Colón, por invitación del Ministerio de Educación Nacional de Colombia. Confiesa Oteiza que la preparación de ambas le obligó a profundizar en el verdadero significado de su obra, que no había sido capaz de desentrañar en el Prado. AFMJO, FD-10698. Pintura de Goya y encuentro con el realismo metafísico del arte español. Año 1946; FD-11021. Del estilo de Goya al Realismo inmóvil. Año 1946; FD-11050. Del estilo de Goya al realismo inmóvil. Año 1946.

${ }^{20}$ Oteiza, 1997.

21 Azanza López, 2013.

22 AFMJO, FD-5991. Oteiza, Roca y César de la Jara junto a la casa del Greco. Toledo, h. 1952.

${ }^{23}$ AFMJO, FD-6049. Aclaraciones sobre mi comportamiento como escultor. Octubre de 1973. Díaz Ereño, 2013: 56.

${ }^{24}$ Oteiza combate el automatismo surrealista porque "no es una escuela o estilo formal auténtico" y tan solo "contribuye a desacreditar las nuevas formas artísticas... es una verdadera superchería". No obstante, reconoce que artistas 

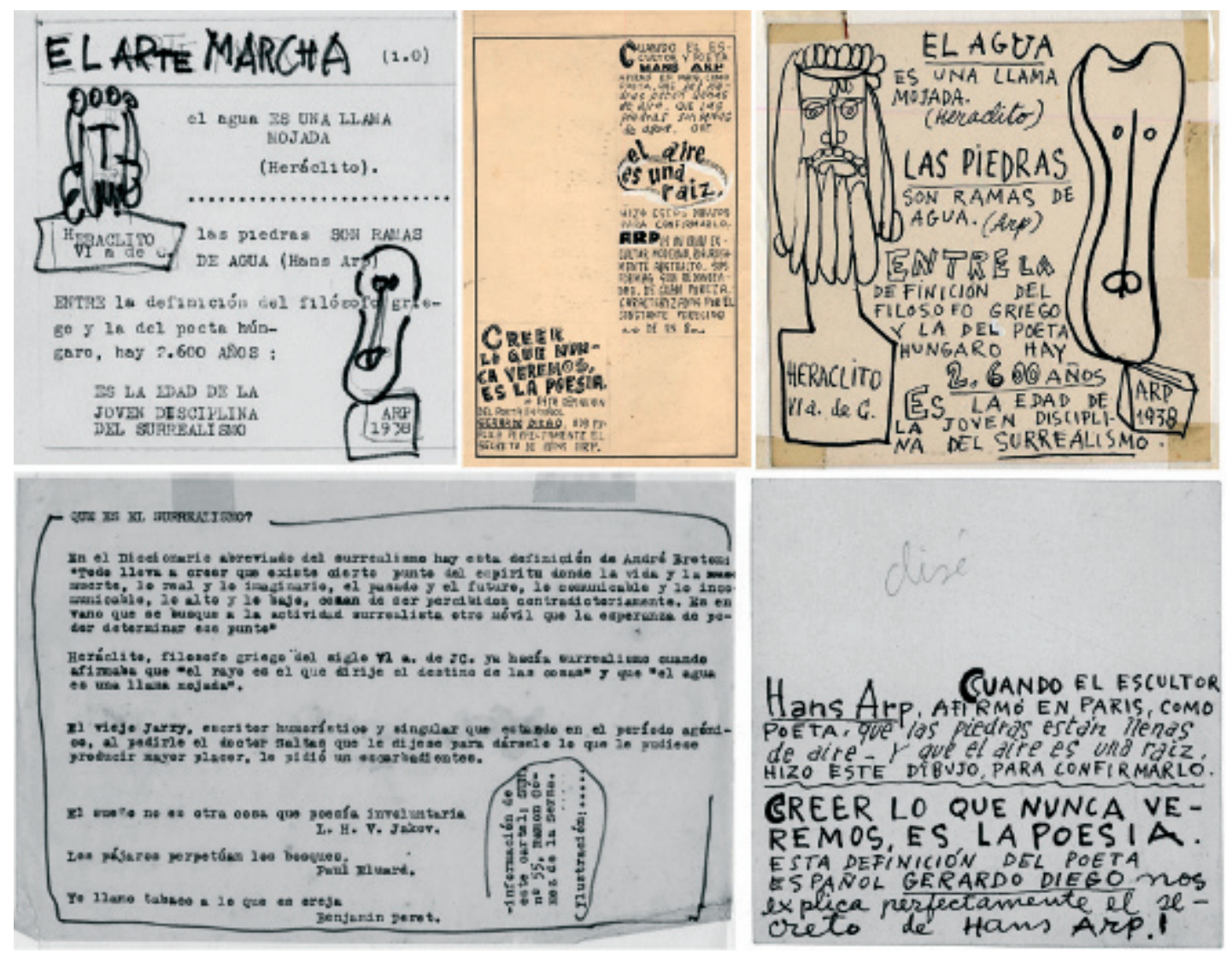

Fig. 4. Jorge Oteiza. Boceto y minutogramas sobre el universo surrealista. AFMJO, FD-14825, FD-14827, FD-22790 y FD-22791.

El punto de partida se encuentra en la definición que proporciona el Diccionario abreviado del surrealismo, publicado por André Breton (1896-1966) y Paul Éluard (1895-1952) con motivo de la Exposición Internacional de Surrealismo celebrada en París en 1938, y que Oteiza transcribe: "Todo lleva a creer que existe cierto punto del espíritu donde la vida y la muerte, lo real y lo imaginario, el pasado y el futuro, lo comunicable y lo incomunicable, lo alto y lo bajo, dejan de ser percibidos contradictoriamente. Es en vano que se busque a la actividad surrealista otro móvil que la esperanza de poder determinar ese punto"25.

Conforme a la anterior definición, considera al filósofo griego Heráclito (siglos VI-V a.C.) como el primer surrealista, merced a sentencias como "el agua es una llama mojada" o "el rayo es el que dirige el destino de las cosas", ambas recogidas en el Diccionario. Y establece a continuación un paralelismo con el poema L'air est une racine (El aire es una raíz) del surrealista Hans Arp (1887-1996), quien describe una naturaleza en clave heraclitana, inmersa en continua metamorfosis en la que cada elemento puede convertirse en otro, ajena a la esclavitud de la ra-

como Dalí o Picasso trabajaron apoyándose en los cánones renacentistas y en la proporción áurea, y de ahí su ambivalencia: "Me he cansado de defender la validez de estos artistas. Pero también estoy cansado de sus viejos trucos y de la farsa del surrealismo tan perjudicial para un entendimiento acertado de las nuevas generaciones". AFMJO, FD-9683. Crítica del surrealismo. Año 1946.

${ }_{25}$ Para las definiciones y sentencias recogidas en el Diccionario abreviado del surrealismo, nos servimos de la edición de Siruela, Madrid, 2003. 
cionalidad y en sintonía con las posibilidades de la definición surrealista de Breton y Éluard ${ }^{26}$; así queda de manifiesto en algunos de sus "versos" citados por Oteiza, como "las piedras son ramas de agua", "las piedras están llenas de aire" y "el aire es una raíz". El escultor vasco contextualiza el poema de Arp en París en 1938, lo cual le lleva a cifrar en 2.600 años "la edad de la joven disciplina del surrealismo", los que transcurren entre el "retrato clásico" de uno y el "contemporáneo" del otro.

Todavía en clave surrealista, Oteiza significa que, cuando Arp dio a conocer su poema, "hizo estos dibujos para confirmarlo"; y los dibujos son el vacío como manera de representar el aire, concepto plenamente vinculado a la plástica y estética oteicianas. Reconoce a continuación que Arp es "un gran escultor moderno, rigurosamente abstracto. Sus formas son redondeadas, de gran pureza, caracterizadas por el constante parecido de un 8", número inspirador de su "retrato". No sorprende el elogio hacia el artista francoalemán, toda vez que en este período se convirtió en uno de sus escultores de referencia junto a Picasso, Brancusi y Lipchitz; atraído por su proceso de indagación, la huella de Arp es perceptible en escritos y obras de su etapa americana, desde los dibujos preparatorios de su conferencia Informe sobre el Encontrismo pronunciada en 1935 en la Academia de Bellas Artes de Santiago de Chile (donde ya alude al "ocho" de Arp junto al "bastón" de Picasso, el "huevo" de Brancusi y el poliedro de Lipchitz) ${ }^{27}$ hasta el Retrato de Luz Valencia (1945); y permanece a su regreso, como comprobamos en la lección "Mito de Dédalo y solución existencial en la Estatua" impartida en el Nuevo Ateneo de Bilbao en 1951, en la que recuerda su conferencia chilena ${ }^{28}$.

El vacío como "imagen" de la poesía de Arp conduce a Oteiza a una nueva afirmación en clave surrealista: "Creer lo que nunca vemos, es la poesía. Esta definición del poeta español Gerardo Diego, nos explica perfectamente el secreto de Hans Arp”. La conexión con Gerardo Diego (1896-1987) se concreta en la última de sus nueve definiciones (una por musa) de la poesía recogidas en su Poética: "Creer lo que no vimos dicen que es fe. Creer lo que nunca veremos es poesía" 29 . Aunque posterior a la redacción de los Minutogramas, la biblioteca oteiciana registra un libro del poeta cántabro: Imagen (Málaga, Centro Cultural de la Generación del 27, 1989, FB-232, Sign. 984), en una de cuyas páginas escribe: "El surrealismo me ha parecido siempre fácil. Poesía fácil del absurdo" (p. 216).

Oteiza concluye su mirada al surrealismo con el pensamiento de otros autores recogidos también en el Diccionario abreviado del surrealismo: "Los pájaros perpetúan los bosques", de Paul Éluard 30; "El sueño no es otra cosa que poesía involuntaria", de L. H. V. Jakob; "Yo llamo tabaco a lo que es oreja", reto en clave magritiana del poeta francés Benjamin Péret (1899-1959). A los anteriores añade una referencia al anecdótico episodio del dramaturgo y poeta francés Alfred Jarry (1873-1907), el cual, agonizando en su lecho de muerte, solicitó al doctor Saltas (18651954) un escarbadientes como último deseo.

A la hora de rastrear las posibles fuentes de Oteiza para todo lo relacionado con el universo surrealista, comprobamos que se encuentra ausente de su biblioteca el Diccionario abreviado del surrealismo. Sin embargo, pudo tener noticia del mismo a través de una reseña firmada en 1939 por Ramón Gómez de la Serna en la sección "Los libros" de la revista Sur, publicada mensual-

${ }^{26}$ Publicado originalmente en Le Surréalisme au service de la Révolution, n. ${ }^{\circ}$ 6, 15 de mayo de 1933, el poema fue traducido por el poeta español Domingo López Torres en Gaceta del Arte (3), n. ${ }^{\circ}$ 24, marzo de 1934, y más tarde por los poetas Aldo Pellegrini y Jesús Munárriz. Dice así: "Las piedras están llenas de entrañas. Bravo. Bravo. Las piedras / están llenas de aire. / Las piedras son ramas de agua. // Sobre la piedra que ocupa el lugar de la boca brota una hoja arista. Bravo. / Una voz de piedra está tête á tête y pie a pie con la mirada de piedra. // Las piedras se atormentan como la carne. / Las piedras son como las nubes, pues su segunda naturaleza las baila / en su tercera nariz. Bravo. Bravo. / Cuando las piedras se limpian las uñas se impulsan hacia sus raíces. / Bravo. Bravo. / Las piedras tienen orejas para comerse la hora exacta". Behar, 1987: 104. Palenzuela, 2006: 21 y 27.

27 AFMJO, FD-22338. Lipchitz, Brancusi, Picasso y Arp.

28 AFMJO, FD-3188. Mito de Dédalo y solución existencial en la Estatua. Año 1951; Álvarez, 2010: 196.

29 La definición aparecía recogida en Diego, 1932: 264-265; y dos años más tarde en Diego, 1934: 397-398.

${ }^{30}$ En realidad la frase de Éluard dice: "Los pájaros perfuman los bosques", por lo que Oteiza introduce una modificación en la misma, desconocemos si voluntaria o involuntariamente. 
Fig. 5. Jorge Oteiza. Minutograma sobre la conversación de los escultores con las piedras. AFMJO, FD-22790.

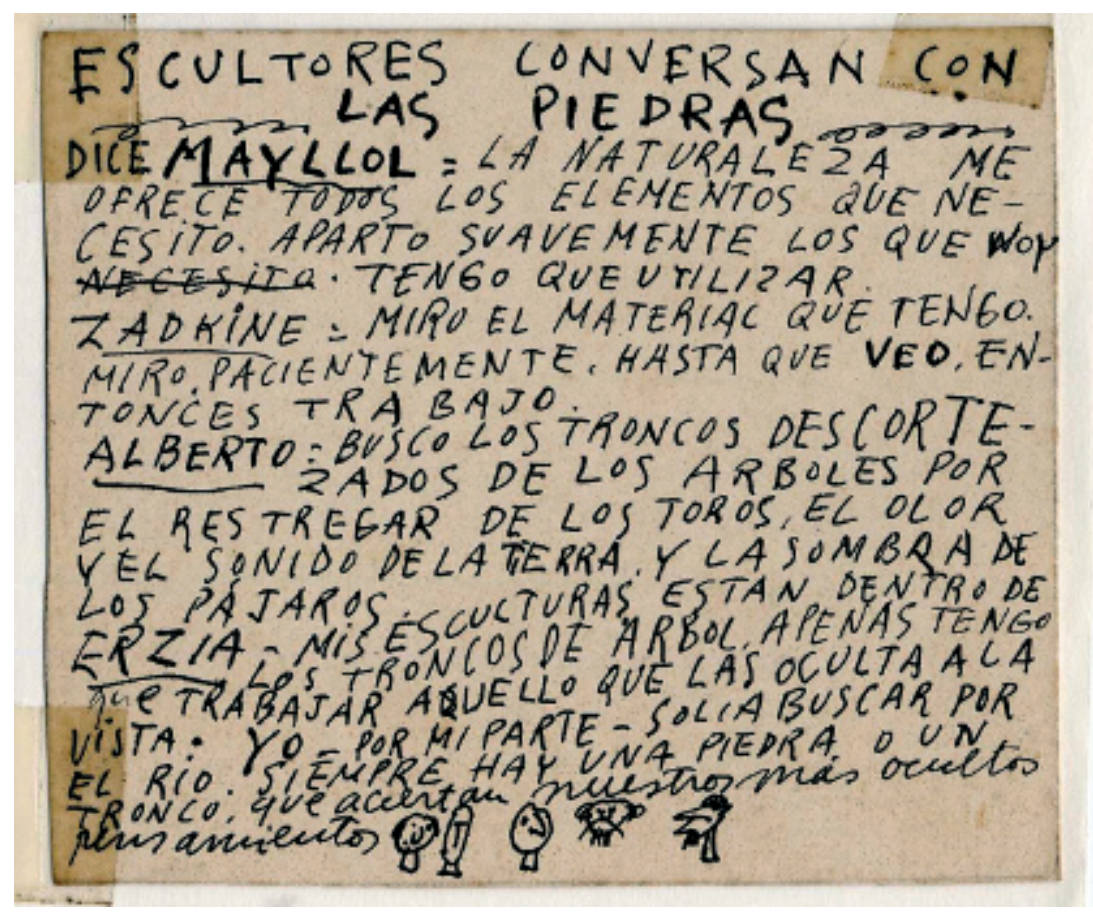

mente en Buenos Aires bajo la dirección de la escritora y editora argentina Victoria Ocampo (1890-1979), cuyo contenido coincide plenamente con el Minutograma ${ }^{31}$.

\section{Los escultores conversan con las piedras}

Entramos ahora en la conversación que cinco escultores mantienen con las piedras, que para Oteiza se concreta en el diálogo de su obra con la naturaleza (fig. 5).

El primero de ellos es el artista francés Aristide Maillol (1861-1944), quien afirma: "La naturaleza me ofrece todos los elementos que necesito. Aparto suavemente los que (no neeesito) tengo que utilizar". Maillol admiraba la belleza de la naturaleza, a propósito de lo cual declaraba que "la dificultad no está en copiar a la naturaleza sino en extraer de ella, cuando se aprendió a copiarla, los elementos de una estatua" 32 . Como bien significa a este respecto Joseph Pla, "escultura y naturaleza son de difícil separación [...] el escultor es un hombre situado dentro de la naturaleza o influenciado por su peso"33.

El segundo es el escultor y pintor ruso Ossip Zadkine (1890-1967), en cuya obra se percibe el poder morfológico de la naturaleza, y de ahí su afirmación recogida por Oteiza: "Miro el material que tengo. Miro, pacientemente, hasta que veo, entonces trabajo"34.

El tercero es Alberto Sánchez (1895-1962), quien manifiesta: "Busco los troncos descortezados de los árboles por el restregar de los toros, el olor y el sonido de la tierra, y la sombra de los pájaros". La frase nos retrotrae a junio de 1933, cuando Alberto publica en la madrileña revista

31 Gómez de la Serna, 1939: 77-80.

32 Maiorana, 2005: 493.

33 Cit. por González Vidal, 1992: 81.

34 Para Zadkine, el poder morfológico de la naturaleza debe estar presente en la obra artística, con independencia de autores: "Ya se trate de Masaccio, Giotto, Greco, Cézanne o Picasso, cada uno de ellos tuvo que formar la apariencia natural de los objetos, y darles la calidad de un mundo imaginario". Maritain, 2004: 60. 
Arte "Palabras de un escultor", manifiesto-poema en prosa que alcanzó una notable difusión ${ }^{35}$. Tal y como explicará años más tarde, su experiencia escultórica surge en esta época de la necesidad de dar con unas formas para las que "no tuve inconveniente alguno en buscar en el campo"36. De este descubrimiento de la naturaleza se desprende la "emoción lítica" que traslada a su manifiesto, cuyo fin último no es otro que alcanzar "un arte revolucionario, que busca la vida"; para ello, exalta como fuente de inspiración a los labradores insertos en el ciclo de la vida rural, expresándose en términos similares a como lo harán poetas como Miguel Hernández o Arturo Serrano Plaja ${ }^{37}$.

Admirado por su integración poética con la naturaleza, Oteiza reconoce en Alberto a uno de sus principales referentes ${ }^{38}$. Al poco de arribar a Hispanoamérica, en Santiago de Chile se le ofreció la oportunidad de escribir en la revista Arquitectura, circunstancia que aprovechó para dar noticia de lo que Alberto significaba en el panorama de la escultura europea; no en vano, conservaba viva en su memoria la obra del artista toledano, como se desprende de sus palabras: "Cuando en 1934 decidí viajar a Suramérica, no me quise ir sin conocer algunas esculturas suyas que no había visto y que tenía en su estudio el arquitecto Lacasa". Y las describe en los mismos términos de "troncos de árbol descortezados" que el Minutograma39.

El cuarto escultor es el ruso Stephan Erzia (1876-1959), quien afirma, en clave miguelangelesca: "Mis esculturas están dentro de los troncos de árbol, apenas tengo que trabajar aquello que las oculta a la vista". Erzia llegó a Argentina en 1927, descubriendo muy poco después la madera, que se convirtió en el material predilecto para sus esculturas, tal y como observaba el diario El Mundo de Buenos Aires en 1931, haciéndose eco del éxito de su muestra en la Galería Muller: "El artista ruso percibe en el bloque primitivo de la madera dura el perfil, la silueta, el esbozo de lo que allí oculta [...] Así las esculturas de Erzia conservan, en todos los casos, la forma natural del árbol". En efecto, el escultor veía en las vetas de la madera las figuras que plasmaba; su respeto por este material marcó su estilo, y así lo reconocía en la revista Aquí está en abril de 1938: "Adiviné al instante las posibilidades que ofrecía para la escultura. La variación de sus coloraciones, rojo, negro, blanco, dan a las figuras un encanto especial" ${ }^{40}$.

A los anteriores se suma el propio Oteiza, quien reconoce: "Yo — por mi parte— solía buscar por el río. Siempre hay una piedra o un tronco que aciertan nuestros más ocultos pensamientos". Recordemos a este respecto que la naturaleza se encuentra en la base del pensamiento oteiciano, quien entiende la búsqueda estética como una inicial salida de la naturaleza que atraviesa por un período de racionalización para volver a entrar de nuevo en ella. Aboga por tanto en sus escritos por la nueva comprensión estética de la naturaleza, en la que encuentra equilibrio y orden, convirtiéndose en vehículo de salvación artística.

El Minutograma se cierra con cinco pequeñas caricaturas, quizás otros tantos "retratos" de los escultores arriba mencionados (podemos "identificar" los de Alberto, Zadkine y Erzia) en los que no faltaría su "autorretrato" en el último de ellos, provisto de sus "barbas profanas" que diferenciaba de las de su hermano Antonio, el capuchino Germán de San Sebastián.

35 Existe una edición facsímil de la revista con prólogo y edición a cargo de Juan Manuel Bonet (2003). El texto de Alberto Sánchez aparece recogido en Sánchez, 1975: 63-67; y en Alberto 1895-1962 (2001).

36 Sánchez, 1975: 46. Carmona, 2001: 131.

37 López García, 2005: 435-436.

38 Identificado con la complejidad que encerraba su obra, Oteiza considera a Alberto "mi maestro" y "el modelo de una vocación original", antes de concluir: "pienso en sus esculturas del tiempo de la República como las más extraordinarias, misteriosas, originales, de todas las que recuerdo del Arte Contemporáneo". AFMJO, FD-3643. Mi reconocimiento a Alberto. Madrid, 7 de enero de 1975; FD-3179. Alberto como escultor y como hombre. Alzuza, 18 de agosto de 1989. Moya, 2010: 127-160.

39 AFMJO, FD-933. Alberto en la memoria del escultor vasco Oteiza; FD-3643. Mi reconocimiento a Alberto. Madrid, 7 de enero de 1975. Muñoa, 2006: 72-73. Díaz Ereño, 2013: 33-34.

40 Gutiérrez Zaldívar, 2003. González Rouco, María, "Rusos”. En Inmigración. Escultura (página 2). En http:// www.monografias.com/trabajos14/esculturainmg/esculturainmg.shtml [Consulta: 30-04-2016]. "Escultor Erzia: vida y destino". En La Voz de Rusia, 20-XI-2011. En: http://mundo.sputniknews.com/spanish_ruvr_ru/radio_broadcast/53074770/60714898/ [Consulta: 30-04-2016]. 


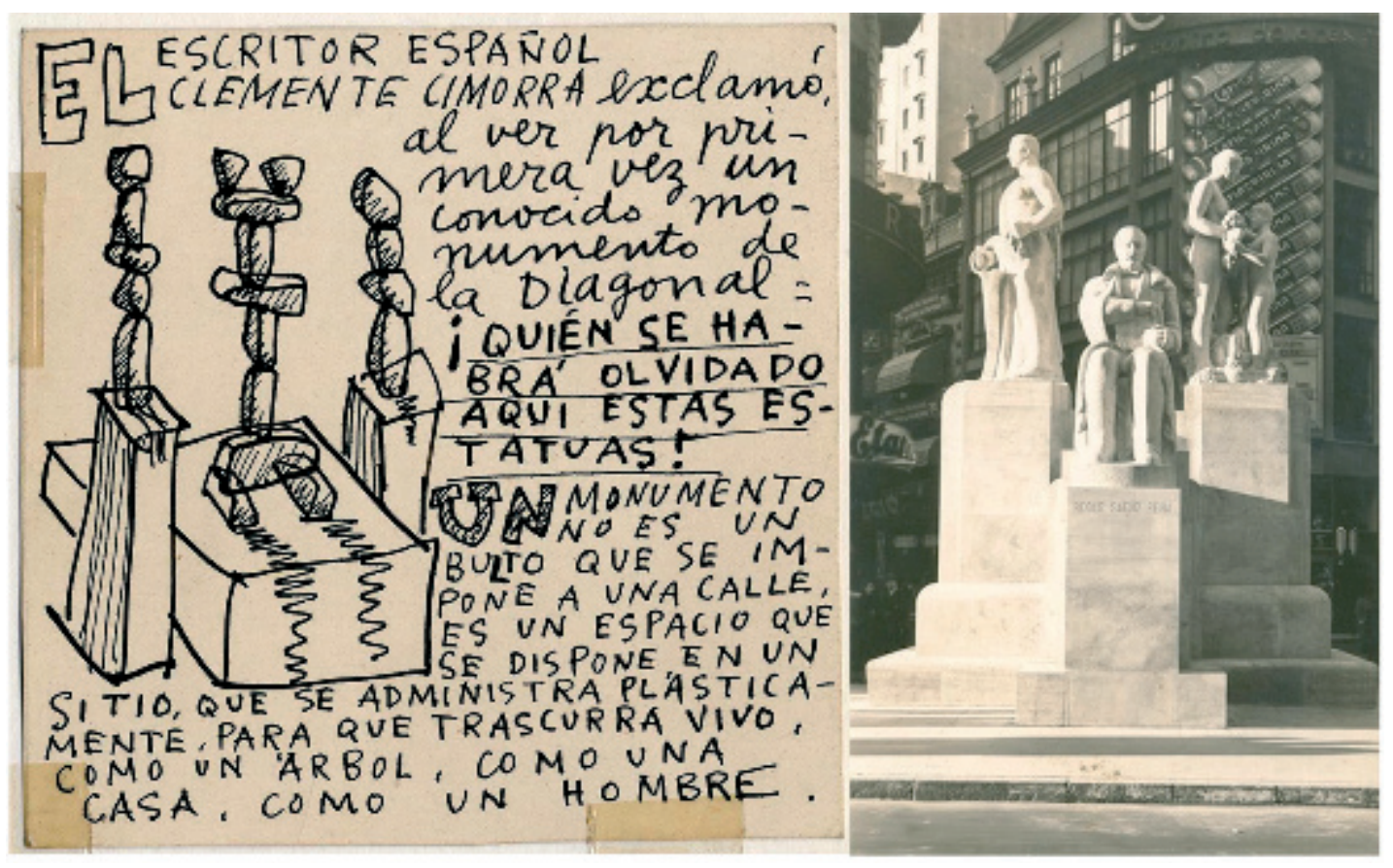

Fig. 6. Jorge Oteiza. Minutograma de Clemente Cimorra. AFMJO, FD-22790. José Fioravanti. Monumento a Roque Sáenz Peña (1936).

\section{Del escritor Clemente Cimorra al escultor Lorenzo Domínguez}

Un nuevo Minutograma hace referencia al periodista y escritor español Clemente Cimorra (1900-1958), exiliado en Buenos Aires en 1939, quien "exclamó al ver por primera vez un conocido monumento de la Diagonal: ¡Quién se habrá olvidado aquí estas estatuas!”. A partir de aquí, Oteiza desarrolla su reflexión personal: "Un monumento no es un bulto que se impone a una calle, es un espacio que se dispone en un sitio, que se administra plásticamente para que trascurra vivo, como un árbol, como una casa, como un hombre" (fig. 6).

La biblioteca oteiciana registra un libro de Cimorra, El cante jondo. Origen y realidad folklórica (Buenos Aires, Schapire, 1943, FB-198, Sign. 702), que firmó en Bogotá en 1946. Pese a su interés por la cuestión de lo "jondo" para la conformación de la estatua ${ }^{41}$, por su fecha no viene al caso. Siguiendo la pista a la ubicación del monumento, la referencia a lo inadecuado de su emplazamiento, e incluso la esquemática y abstracta composición que realiza del mismo, con un elemento central flanqueado por otras dos estructuras y todo sobre pedestales, podemos aventurar una hipótesis acerca del conjunto escultórico protagonista del Minutograma. Nos decantamos por el Monumento a Roque Sáenz Peña (1851-1914), abogado y político argentino que llegó a ocupar la presidencia de la nación, esculpido en París por el argentino José Fioravanti (1896-1977) e inaugurado en Buenos Aires en 1936. En él, la figura sedente de Sáenz Peña queda enmarcada por sendos grupos alegóricos que simbolizan La Acogida y El Voto secreto, universal y obligatorio, instaurado bajo su presidencia ${ }^{42}$.

El conjunto se ubica en la pequeña plazoleta Ciriaco Ortiz, próximo a la fachada principal del antiguo edificio del Banco de Boston, en una de las esquinas más transitadas de la capital forma-

41 Pavo Cuadrado, 2014: 198-211.

42 Rodríguez, 1963: 17-18. Sáenz Quesada, 2014: s.p. 


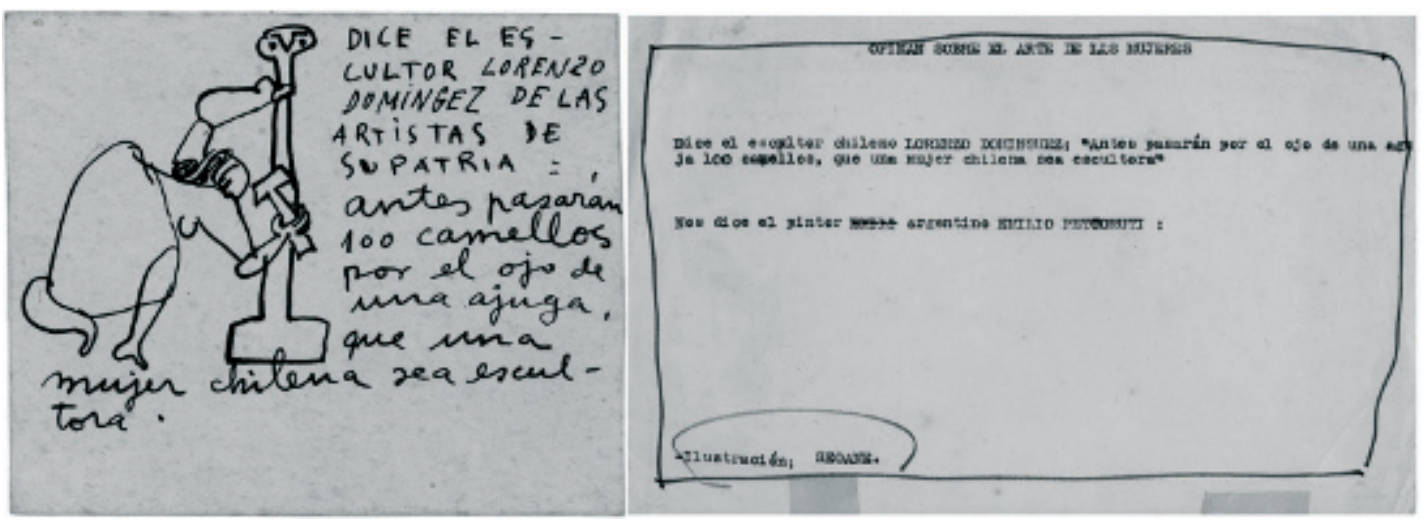

Fig. 7. Jorge Oteiza. Minutograma y boceto de Lorenzo Domínguez. AFMJO, FD-22791 y FD-14825.

da por la intersección de las calles Florida, Bartolomé Mitre y Diagonal Norte (cuyo verdadero nombre es Avenida Presidente Roque Sáenz Peña). Precisamente por tratarse de un lugar de paso, dificulta el tránsito de peatones, a la vez que carece de la perspectiva necesaria para su contemplación y resulta imposible el diálogo con su entorno.

La reflexión encaja con el concepto de monumento urbano que tiene Oteiza, para quien el emplazamiento constituye una cuestión clave; nos encontramos ante una constante en sus proyectos de escala urbana, como es el interés concedido a las condiciones del lugar que lo acoge. Así queda de manifiesto en su propuesta de monumento a Felipe IV (1949), donde asegura que la primera condición de todo monumento erigido en la vía pública es la de no estorbar con una inadecuada ubicación ${ }^{43}$.

Otro Minutograma recoge la opinión que le merece al escultor chileno Lorenzo Domínguez Villar (1901-1963) la actividad escultórica de las mujeres de su país: "Dice el escultor Lorenzo Domínguez de las artistas de su patria: antes pasarán 100 camellos por el ojo de una aguja, que una mujer chilena sea escultora" (fig. 7). Tal afirmación se inscribe en una entrevista de la periodista Georgina Durand, seudónimo de Raquel Delaporte Prieto, publicada en La Nación el 21 de mayo de $1939^{44}$. En el transcurso de la misma el escultor, recién llegado de su periplo europeo que le había conducido a Barcelona, Londres y París - con una admiración incondicional hacia Maillol-, expone su concepto de escultura, analiza las relaciones arte-política y ofrece su visión del arte en la vida cultural chilena; y, preguntado por el papel de la mujer artista, refiere la periodista que "no desea personalizar, pero nos afirma que primero pasará un rebaño de camellos por el ojo de una aguja antes de que una mujer chilena sea escultora".

En relación con el anterior, un documento mecanoscrito lleva por título "Opinan sobre el arte de las mujeres", y recoge sin apenas variantes la afirmación de Domínguez. A ella debía sumarse otra, pues escribe Oteiza: "Nos dice el pintor argentino Emilio Pettoruti...", sin que lleguemos a conocer el pensamiento de este último, pues la frase finaliza aquí.

\section{Biografía de la pintora Maruja Mallo}

Oteiza dedica uno de sus Minutogramas a la pintora surrealista Maruja Mallo (1902-1995), "retrato" incluido, en el que resume en cuatro estaciones "el viaje de integración con el nuevo universo plástico en la obra de la moderna pintora española", marcadas por otros tantos años:

43 Azanza López, 2013: 40-41.

44 Durand, 1939: 4. 


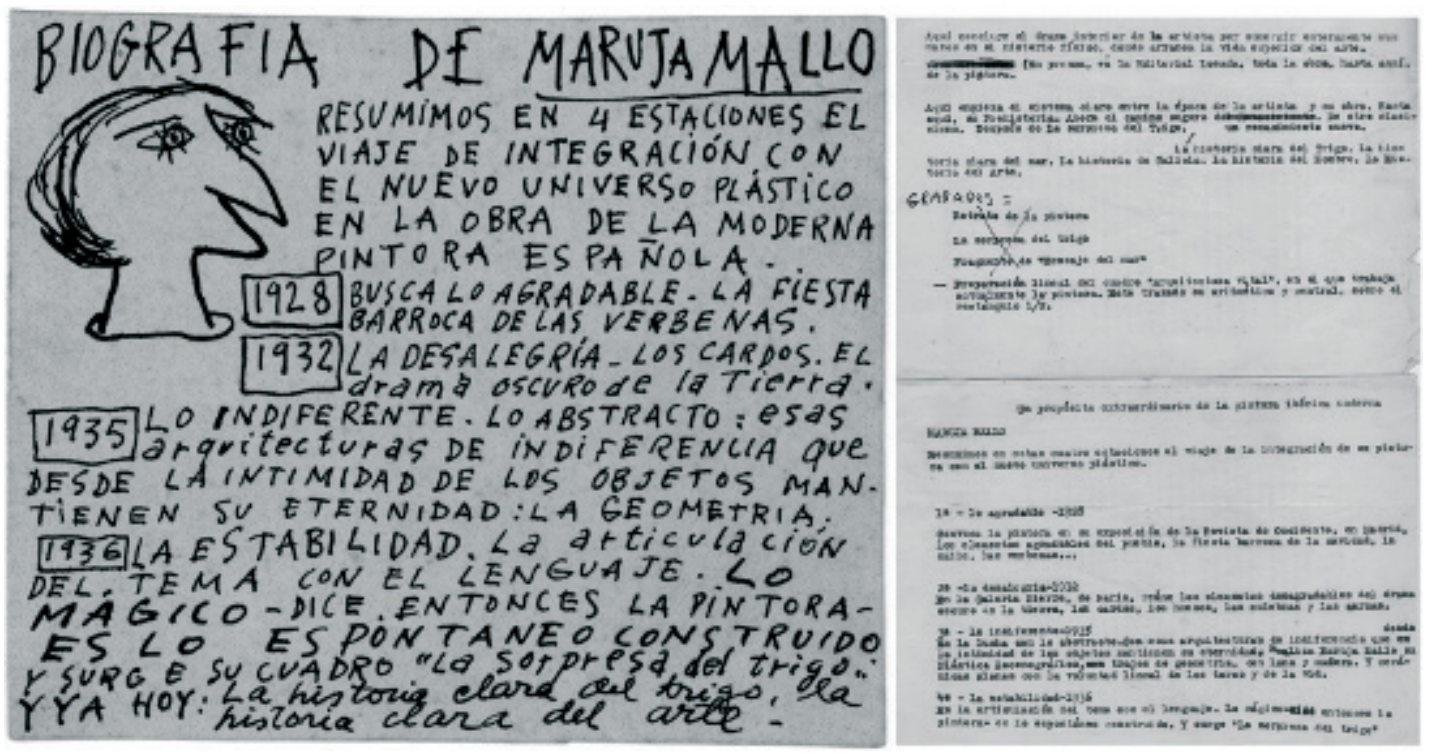

Fig. 8. Jorge Oteiza. Minutograma y boceto de Maruja Mallo. AFMJO, FD-22791 y FD-15070.

1928, 1932, 1935 y 1936. El resultado final es "ya hoy: la historia clara del trigo, la historia clara del arte" (fig. 8).

Este rápido recorrido no es sino la síntesis de un libro cuyo texto firma Maruja Mallo en Buenos Aires el 31 de diciembre de 1937, y que figura en la biblioteca personal oteiciana: Lo popular en la plástica española a través de mi obra (Buenos Aires, Losada, 1939, FB-4047, Sign. 3559); parece que Oteiza lo leyó cuando todavía se encontraba en prensa, según reconoce en un documento en el que resume de nuevo sus etapas ${ }^{45}$. En el mismo, la artista analiza la evolución de su pintura que parte del realismo objetivo (1928), avanza hacia la destrucción objetiva (1932) y culmina en la realidad subjetiva (1936) basada en el orden universal de la naturaleza y el ansia arquitectónica (lo que el escultor entiende como "historia clara del arte"). Oteiza contaba con otro libro, Maruja Mallo (Buenos Aires, Losada, 1942, FB-513, Sign. 1844) de Ramón Gómez de la Serna, posterior a la redacción del Minutograma.

Debemos tener presente la amistad entre escultor y pintora, que se remonta a la etapa de formación del primero en Madrid y se mantiene más tarde en América, como rememora: "Recuerdo cómo M(aruja) M(allo) administraba su semana en B. Aires, los jueves esperaba a Ramón G. de la Serna, a mí me correspondía los viernes, su excelente cocinera gallega me preparaba siempre alguna caxuelita vasca. Y toda la noche conversando de arte. Me interrumpía Maruja: aguarda un momento, y anotaba en su cuaderno"46. La relación tiene su reflejo en diversos textos, cartas y fotografías a través de los cuales conocemos la opinión del escultor sobre la pintora ("su Biblia era Platón y su estética la reglamentación áurea más ortodoxa"), la vemos en su estudio rodeada de sus cuadros, o tenemos noticia de los consejos que le da para que, una vez regresado a España en 1948, continúe con su vocación escultórica en París ${ }^{47}$.

45 AFMJO, FD-15070. Maruja Mallo.

46 AFMJO, FD-6818. Chillida y Maruja Mallo.

47 AFMJO, FD-6818. Chillida y Maruja Mallo; FD-22335. Maruja Mallo en su estudio, rodeada de sus cuadros; FD-9123. Carta de Maruja Mallo a Jorge Oteiza. Buenos Aires, 6 de diciembre de 1948; FD-9124. Carta de Maruja Mallo a Jorge Oteiza. Buenos Aires, 15 de enero de 1949. 


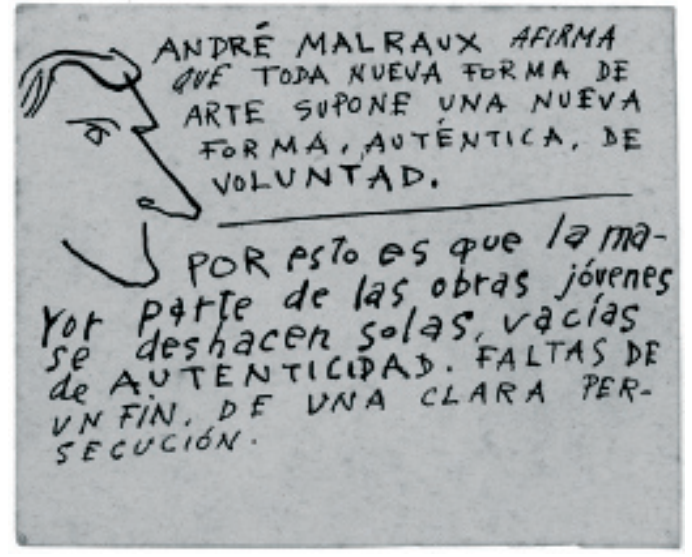

Fig. 9. Jorge Oteiza. Minutograma sobre la forma de arte y André Malraux. AFMJO, FD-22791.

Fig. 10. Jorge Oteiza. Minutograma sobre la materia plástica. AFMJO, FD-22790.

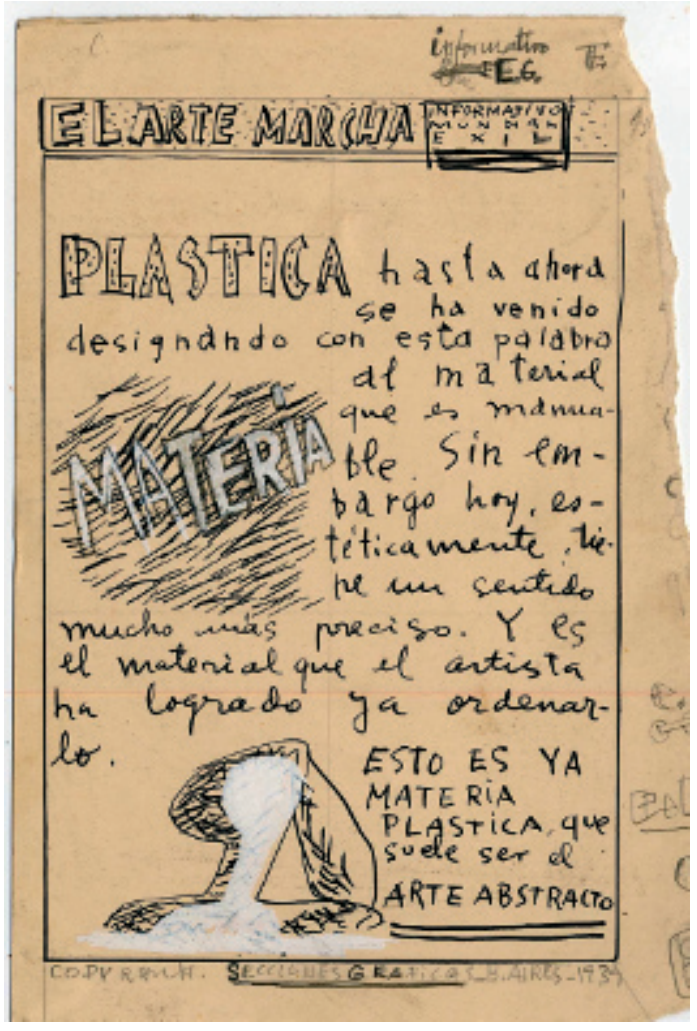

\section{Reflexiones oteicianas en torno al arte y la plástica, el lenguaje y la expresión}

Protagoniza uno de los Minutogramas un pensamiento del teórico francés André Malraux (1901-1976), quien afirma que "toda nueva forma de arte supone una nueva forma, auténtica, de voluntad"; cualidades que sin embargo se encuentran ausentes en la mayor parte de las obras jóvenes, por cuanto carecen de un fin (fig. 9). La biblioteca personal de Oteiza registra tres libros de Malraux editados con posterioridad a $1939^{48}$, por lo que quedan descartados como posible fuente de información; pero ponen de manifiesto el interés del escultor guipuzcoano por la obra del teórico francés.

En otro Minutograma Oteiza facilita su definición de plástica: "Hasta ahora se ha venido designando con esta palabra al material que es manuable. Sin embargo hoy, estéticamente, tiene un sentido mucho más preciso. Y es el material que el artista ha logrado ya ordenarlo. Esto es ya materia plástica, que suele ser el arte abstracto" (fig. 10). Aborda aquí la cuestión de la plástica, a la que dedicó numerosas reflexiones desde el terreno de la estética. En esta ocasión vincula el término a la intervención del artista, cuya ordenación de la materia deviene en arte abstracto; y es que para Oteiza, el orden abstracto en que se acomodan las formas constituye el universo de un objeto plástico.

Una nueva reflexión tiene por objeto la capacidad comunicativa del arte:

"En una cita de Gómez de la Serna, dice von der Gabelentz: 'el lenguaje no sirve solamente al hombre para expresar alguna cosa, sino también para expresarse él mismo’. Es que los medios

48 Malraux par lui-même, Paris, Éditions du Seuil, 1953, FB-1803, Sign. 1837; Psicología del cine. El hombre y la cultura artística, Buenos Aires, JI, 1959, FB-5063, Sign. 4593; y Antimemorias, Buenos Aires, Sur, 1968, FB-1802, Sign. 1836. 
Fig. 11. Jorge Oteiza. Minutograma sobre el lenguaje y la expresión artística. AFMJO, FD-22790.

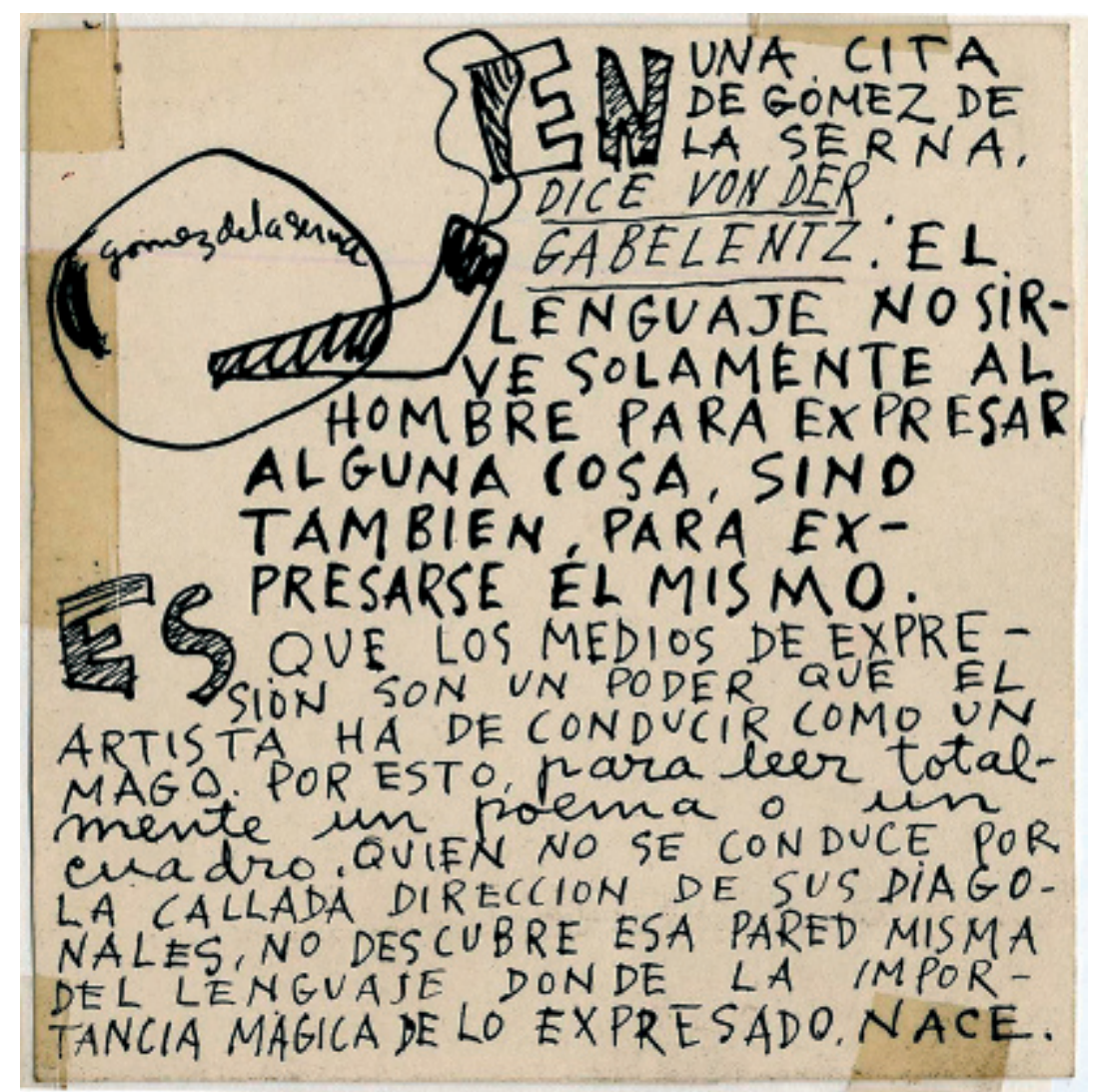

de expresión son un poder que el artista ha de conducir como un mago. Por esto, para leer totalmente un poema o un cuadro, quien no se conduce por la callada dirección de sus diagonales, no descubre esa pared misma del lenguaje donde la importancia mágica de lo expresado, nace" (fig. 11).

Oteiza acompaña el texto de un "retrato" de Gómez de la Serna al que identifica por su característica pipa y por su apellido con el que "dibuja" las cejas. Al igual que el hombre es inseparable de su lenguaje, el artista lo debe ser de su obra, a través de la cual adquiere la capacidad de expresarse. La reflexión parte del pensamiento del lingüista alemán Georg von der Gabelentz (1840-1893), el cual formuló su defensa del lenguaje de este modo: "La lengua no sirve solamente al hombre para expresar alguna cosa, sino también para expresarse a sí mismo". Oteiza llega al mismo a través de Ramón Gómez de la Serna. A la hora de establecer la posible conexión, tenemos que dirigir de nuevo la mirada hacia la reseña del Diccionario abreviado del surrealismo firmada por el escritor español en 1939, y que concluía precisamente con la cita textual de von der Gabelentz ${ }^{49}$, lo cual reafirma la hipótesis de que conoció y manejó dicho texto.

\section{Minutogramas más allá del arte}

Además de aquellos con contenido estético-artístico, Oteiza concibió, con mayor o menor grado de acabado, otro conjunto de Minutogramas que abarcan desde lo histórico y cultural

49 Gómez de la Serna, 1939: 80. 


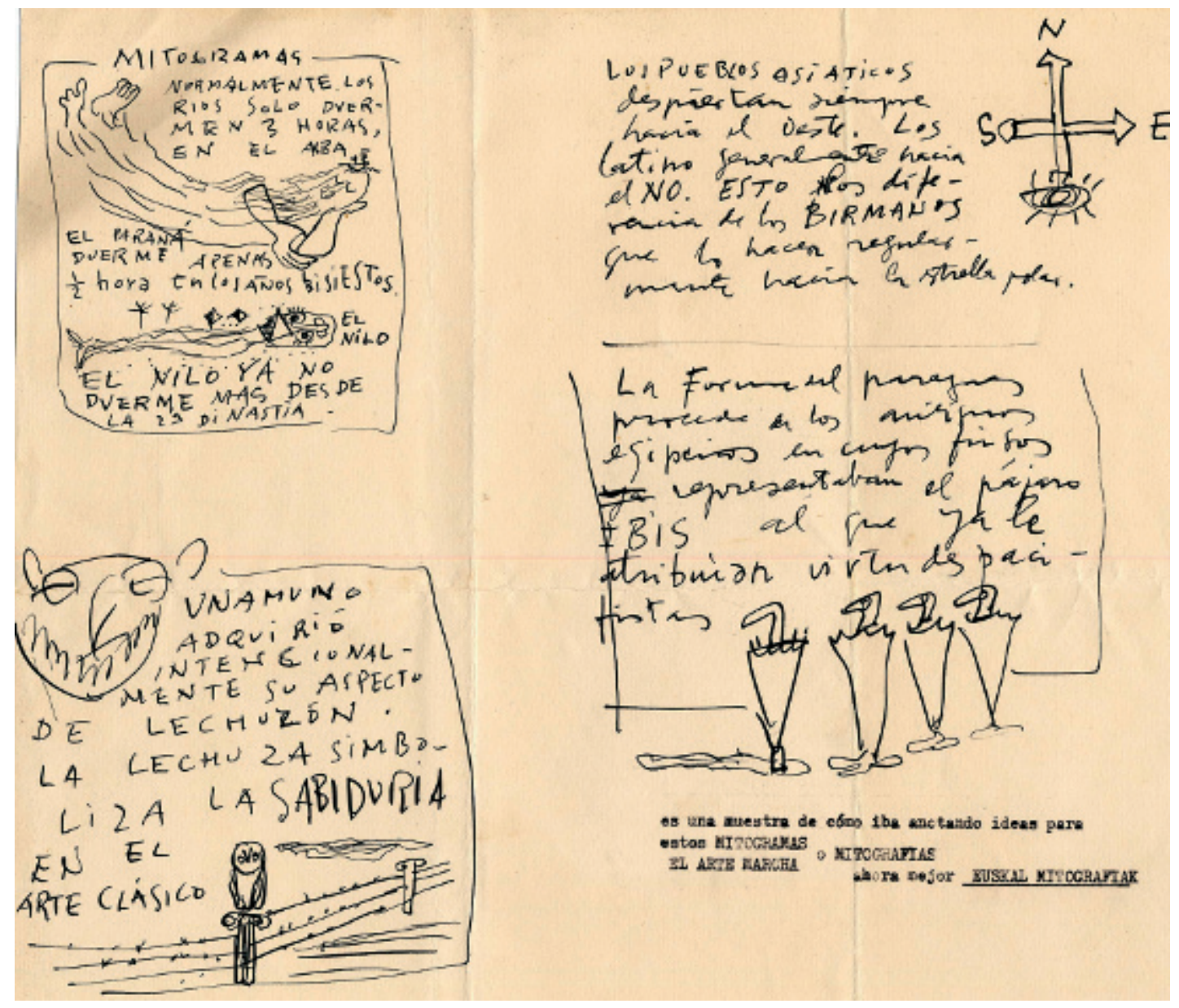

Fig. 12. Jorge Oteiza. Boceto de minutogramas sobre diversos asuntos. AFMJO, FD-22790.

hasta lo sociológico, geográfico y antropológico, y que constituyen "una muestra de cómo iba anotando ideas para estos mitogramas o mitografías, ahora mejor Euskal Mitografiak" (fig. 12).

El más reiterado es el que alude a Miguel de Unamuno (1864-1936), del que, con mínimas variantes, afirma que "adquirió intencionalmente su aspecto de lechuzón", para recordar a continuación que "la lechuza simboliza la sabiduría en el arte clásico". Los textos se acompañan del "retrato" a medio camino entre hombre y ave, junto al cual figura una lechuza que descansa sobre los postes de un cableado que adquieren forma de columnas jónicas, quizás para reforzar el carácter clásico del símbolo. Debemos significar que Oteiza lee (hasta una treintena de libros en su biblioteca personal) y escribe sobre Unamuno, dedicando uno de sus documentos a recordar que "Unamuno se parece a una lechuza" 50 , de manera que vuelve a incidir en el tema del Minutograma.

Incluye igualmente una referencia a Napoleón II, del que afirma que "no creía en la osteología", acompañándolo de un esquemático dibujo en el que parece adoptar un físonomía invertebrada a modo de ave, en referencia al sobrenombre de "El aguilucho" con el que fue conocido.

Otros Minutogramas se mueven en el terreno de la geografía y la naturaleza, en ocasiones con un tono entre legendario y surrealista. A esta categoría corresponden el tigre de bengala que

${ }^{50}$ AFMJO, FD-3162. [Unamuno se parece a la lechuza]. 
se lanza sobre sus víctimas como una luz; los ratones protegidos de toda enfermedad pulmonar merced a la "secretación nasal" de una sustancia misteriosa por parte de 31 adultos; la costumbre de ballenas y elefantes de morir del lado que menos les duele; las plantas que crecen a una velocidad de un metro cada cien años, a las que si se les coloca un cerebro humano les sale una hoja con la inscripción. $1+1=3$; la leyenda del triste canto que emiten al morir ciertos ríos del Sudán; o la de las tres horas que duermen los ríos en el alba, a diferencia del río Paraná que apenas duerme media hora en los años bisiestos, y del Nilo, que ya no duerme más desde la 23 Dinastía.

Añadamos la costumbre de los pueblos asiáticos, latinos y birmanos de despertar orientados hacia distintos puntos cardinales; los ritos mortuorios de los árabes y de ciertas tribus asiáticas; la leyenda del sacerdote hindú que construyó una jaula del tamaño de una casa con un cartel anunciador de libertad; y las propiedades del paraguas, cuya forma procede de los antiguos frisos egipcios que representaban al ibis, y abierto del revés permite comprobar la ley de la gravitación universal.

\section{Conclusiones}

"Este interesante, original y valioso servicio que le facilitamos habrá de aumentar, sin duda, el número de sus lectores y, en consecuencia, su publicidad". Así finalizaba Oteiza el borrador de carta por medio de la cual ofrecía a los directores de prensa los servicios de El arte marcha, dentro de la Agencia Internacional de Arte AIDA.

Más de tres cuartos de siglo después, nos hemos "suscrito" a los Minutogramas en los que, con ese gusto tan oteiciano por el grafismo, el escultor vasco nos aproxima, en pequeñas píldoras, a sus ideas artísticas, en un momento todavía de búsqueda de su propia formulación estética. En este contexto, los Minutogramas constituyen, en cierta manera, una declaración de principios, una especie de "credo" a través de cuyos artículos sienta algunas bases de su futuro pensamiento y quehacer artísticos. Y es ahí donde radica la importancia del material.

Comprobamos así que Oteiza se juramenta, de la mano de Leonardo y de Matila Ghyka, con los principios de la geometría basados en la sección áurea. Define asimismo su concepto estético de materia plástica y forma (André Malraux), y concreta una de las premisas básicas de la escultura urbana como es su adecuado emplazamiento, que tan presente estará en posteriores proyectos. Reconoce en El Greco, Velázquez y Goya a sus referentes nacionales, y ve en Cézanne al iniciador del Arte Contemporáneo. Muestra afinidad con aquellos escultores para quienes la naturaleza constituye el fundamento de su trabajo, en una relación que cierra él mismo, para quien la escultura vive en la naturaleza y su experiencia estética es sinónimo de salvación artística. En el ámbito del surrealismo, sigue de cerca su Diccionario abreviado, y se siente atraído por la doble faceta poético-artística de Hans Arp y por Maruja Mallo.

Más allá del plano artístico, los Minutogramas testimonian su dimensión humanista que abarca múltiples áreas de conocimiento; así se deduce de sus referencias históricas (Napoleón, Napoleón II), filosóficas (Heráclito), astronómicas (Kepler), literarias y periodísticas (Unamuno, Ramón Gómez de la Serna, Clemente Cimorra) o lingüísticas (Georg von der Gabelentz). No se trata de un mero alarde enciclopédico, sino de disciplinas y saberes perfectamente imbricados en su pensamiento estético.

En definitiva, los Minutogramas constituyen una pieza más de ese puzzle caleidoscópico y poliédrico que es Oteiza, y marcan la pauta, en fecha temprana, de su posterior evolución ${ }^{51}$.

51 Deseo expresar mi agradecimiento al Museo Fundación Jorge Oteiza de Alzuza, en especial al responsable de su Centro de Documentación, Borja González Riera, por la amabilidad con que atendió mis consultas. 


\section{BIBLIOGRAFÍA}

Alberto 1895-1962 (2001). Madrid: Museo Nacional Centro de Arte Reina Sofía.

Álvarez, Soledad (2003): Jorge Oteiza. Pasión y razón. San Sebastián: Nerea.

Álvarez, Soledad (2010): "Clasicismo y vanguardias en la escultura de Oteiza". En: Oteiza y la crisis de la modernidad. Alzuza: Fundación Museo Jorge Oteiza, pp. 187-216.

Arias, Alfredo (2001): "Prólogo". En: Zlotescu, Ioana (ed.), Ramón Gómez de la Serna. Obras completas VII. Ramonismo V. Barcelona: Círculo de Lectores y Galaxia Gutenberg, pp. 11-58.

Azanza López, J. J. (2013): Crónica de un fracaso: Jorge Oteiza, Felipe IV y el VIII Centenario de San Sebastián (1950). Cuadernos del Museo Oteiza, n. ${ }^{\circ}$ 8. Pamplona: Fundación Museo Jorge Oteiza.

Badiola, Txomin (2015): Oteiza. Catálogo razonado de escultura, Vol. I. Obra figurativa. Alzuza: Fundación Museo Jorge Oteiza.

Behar, Henri (1987): “Arp surréaliste”. En: Cahiers du Centre de Recherche sur le Surréalisme. Mélusine, $n .^{\circ} I X$. Arp poète plasticien. Paris: Editions L'Age d'Homme, pp. 99-112.

Bonet, Juan Manuel (ed.) (2003): Arte. Revista de la Sociedad de Artistas Ibéricos, Madrid, 1932-1933. Madrid: Renacimiento.

Carmona, Eugenio (2001): “Tres consideraciones sobre la Escuela de Vallecas”. En: Alberto 1895-1962. Madrid: Museo Nacional Centro de Arte Reina Sofía, pp. 123-138.

Díaz Ereño, Gregorio (2010): “Mi piedra de catalejo". En: Exposición Oteiza 1935-1975. La casa del Ser. Valladolid: Caja de Burgos, s.p.

Díaz Ereño, Gregorio (2013): "Desde mi pequeño crómlech". En Museo Oteiza. Alzuza: Fundación Museo Oteiza Fundazio Museoa, pp. 25-59.

Diccionario abreviado del surrealismo (2003). Madrid: Siruela.

Diego, Gerardo (1932): Poesía española. Antología 1915-1931. Madrid: Signo (Madrid: Visor Libros, 2002).

Diego, Gerardo (1934): Poesía española. Antología (contemporáneos). Madrid: Signo.

Durand, Georgina (1939): “Entrevistas de La Nación”. En La Nación, 21-V-1939: 4.

Gómez de la Serna, Ramón (1939): "Diccionario Abreviado del Surrealismo". En: Sur. Revista mensual, n. ${ }^{\circ}$ 52-57, Buenos Aires, pp. 77-80.

González Vidal, José Mariano (1992): "Elogio de la escultura o apoteosis de la carne”. En: Papeles Murcianos, Op. 7, Murcia, pp. 79-84.

Gutiérrez Zaldívar, Ignacio (2003): Erzia. Buenos Aires: Zurbarán Editores.

López Bahut, Emma (2016): Jorge Oteiza y lo arquitectónico. De la estatua-masa al espacio urbano (1948-1960). Alzuza: Fundación Museo Jorge Oteiza y Universidade da Coruña.

López García, José Ramón (2005): Vanguardia, revolución y exilio: la poesía de Arturo Serrano Plaja (1929-1945), Vol. I. Barcelona: Universidad Autònoma de Barcelona.

Maiorana, María Teresa (2005): "La meditación”. En: Estudios, reflexiones, miradas de una comparatista. Buenos Aires: Biblos, pp. 492-493.

Maritain, Jacques (2004): La intuición creadora en el arte y en la poesía. Madrid: Palabra.

Martínez Gorriarán, Carlos (2011): Jorge Oteiza, hacedor de vacíos. Madrid: Marcial Pons.

Moya, Adelina (2010): “Oteiza y Alberto. Un modo de entender la función del arte”. En: VV.AA.: Forma, signo y realidad. Escultura española 1900-1935. Alzuza: Fundación Museo Jorge Oteiza, pp. 127-160.

Muñoa, Pilar (2006): Oteiza. La vida como experimento. Irún: Alberdania.

Oteiza, Jorge (1997): Goya mañana. El realismo inmóvil. El Greco. Goya. Picasso. Alzuza: Fundación Museo Jorge Oteiza.

Palenzuela, Nilo (2006): "Vértigos. Vestigios. Transgresiones". En: Jean Arp. Retrospectiva, 1915-1966. Madrid: Círculo de Bellas Artes, pp. 21-29.

Pavo Cuadrado, David (2014): "La materia abstracta configurada en la estatua como común y popular: una reflexión desde Jorge Oteiza". En: AusArt Journal for Research in Art, 3, 2, pp. 198-211.

Rodríguez, Ernesto B. (1963): José Fioravanti. Buenos Aires: Ediciones Culturales Argentinas.

Sáenz Guerra, Javier (2007): Un mito moderno. Una capilla en el Camino de Santiago. Sáenz de Oiza, Oteiza y Romaní, 1954. Alzuza: Fundación Museo Jorge Oteiza.

Sáenz Quesada, María (2014): Roque Sáenz Peña: el presidente que forjó la democracia moderna. Buenos Aires: Sudamericana.

Sánchez, Alberto (1975): Palabras de un escultor. Valencia: Fernando Torres Editor.

Sánchez Simón, Ignacio (2012): Oteiza y los nuevos paradigmas científicos. Alzuza: Fundación Museo Oteiza Fundazio Museoa.

Fecha de recepción: 28-VI-2016

Fecha de aceptación: 03-II-2017 